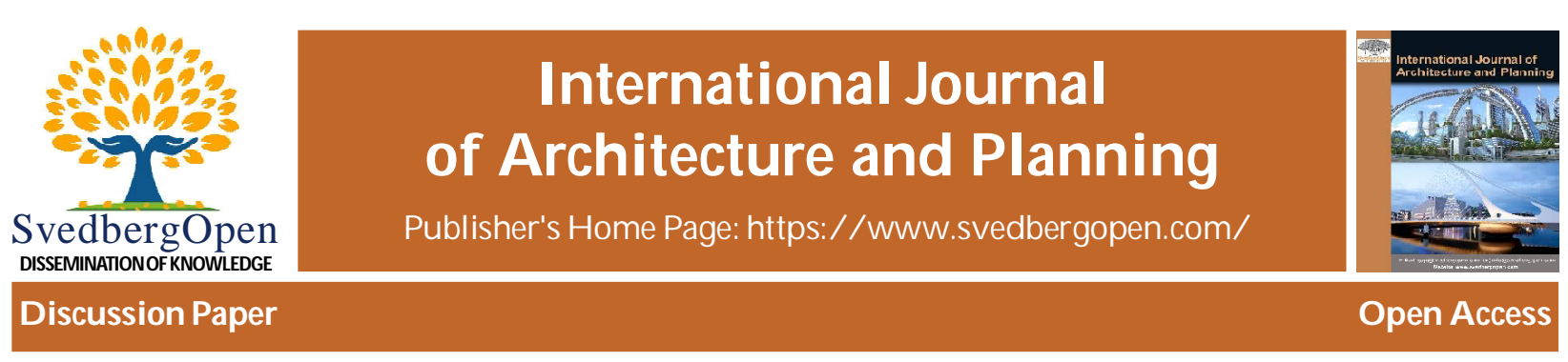

\title{
Why our ancestor has accepted a circular shaped house?
}

\author{
Saurav Koirala ${ }^{1 *}$
}

${ }^{1}$ Fifth Year First Part, Bachelor's Degree in Architecture, IOE Thapathali Campus, Kathmandu, Nepal. E-mail: koiralas874@gmail.com

\section{Article Info}

Volume 1, Issue 1, March 2021

Received : 12 December 2020

Accepted : 15 February 2021

Published : 05 March 2021

doi: 10.51483/IJARP.1.1.2021.24-29

\begin{abstract}
Shelter is one of the basic ways of making the world hospitable to humans, that's why humans have developed the skill of building shelter in a beautiful way, and has been transferred from generation to generation. Now, this architecture is taken as an art. The oldest form of shelter made by humans were almost circular. Some of the representative examples of indigenous circular shelter around the world are Southwest American hogan, the Mongolian yurt, the North American tepee and Nepali Gol/Kudule Ghar. The main reason behind building circular shaped shelter is the influence of what they see around the environment of Mother Nature. The shape of most of the natural elements is curve or circular, for e.g., stones, tree trunks, eggs and the shape of earth itself (is said to be round). Humans were also inspired to build circular houses from the shelter made by other animals (caves) and birds (nests) around their environment. According to architecture and science, circular shaped houses are more comfortable, more energy efficient and safer.
\end{abstract}

Keywords: Vernacular architecture, Identity, Shelter, Circular shaped house, Environment, culture, Building materials, Construction technology, Local characters

(C) 2021 International Journal of Architecture and Planning. This is an open access article under the CC BY license (https://creativecommons.org/licenses/by/4.0/), which permits unrestricted use, distribution, and reproduction in any medium, provided you give appropriate credit to the original author(s) and the source, provide a link to the Creative Commons license, and indicate if changes were made.

\section{Introduction}

Building shelter is a very important skill, as shelter is one of the most basic ways to build the world, in terms that make it friendly to human (Rush, 2012). The knowledge of crafting buildings was developed in one generation and transferred to another generation. This skill of building shelter in a beautiful way can be collectively called as an architecture and is now considered as an art.

The oldest form of shelters made by human was almost circular. Southwest American hogan, the Mongolian yurt, the North American tepee, the Greek temenos and Nepali Gol/Kudule Ghar are some of the representative example of indigenous shelter around the world (Inhabitat, 2017).

The main aim of this paper is to identify the main reason behind why our ancestor had chosen and accepted to build circular shaped house. Since, circular shaped houses were not developed particularly at one place, but around the whole world with different names and same architecture using locally available materials and own construction technology. In modern days, circular shaped house gains popularity for many reasons with the use of modern building materials and construction technologies.

\section{Discussion}

Vernacular architecture is any kind of shelter build by human beings to protect from surrounding environmental conditions using locally available materials utilizing own construction technologies. Vernacular architecture is built to fulfill the

\footnotetext{
* Corresponding author: Saurav Koirala, Fifth Year First Part, Bachelor's Degree in Architecture, IOE Thapathali Campus, Kathmandu, Nepal.E-mail: koiralas874@gmail.com
} 
specific needs in accordance with the economic status and cultural value. Every place and community has their own vernacular architecture which is their identity. Architecture around the world varies due to different factors such as climatic conditions, locally available materials, local building customs, construction technologies and cultural values.

One of the most common ancient styles of architecture which is in practice around the world till now is circular shaped house.

As mentioned earlier, the oldest form of shelters made by humans were almost circular. Southwest American hogan, the Mongolian yurt, the North American tepee, Arctic Igloo, the Greek temenos and Nepali Gol/Kudule Ghar are some of the representative example of indigenous shelter around the world (Inhabitat, 2017) in terms of function and efficiency.
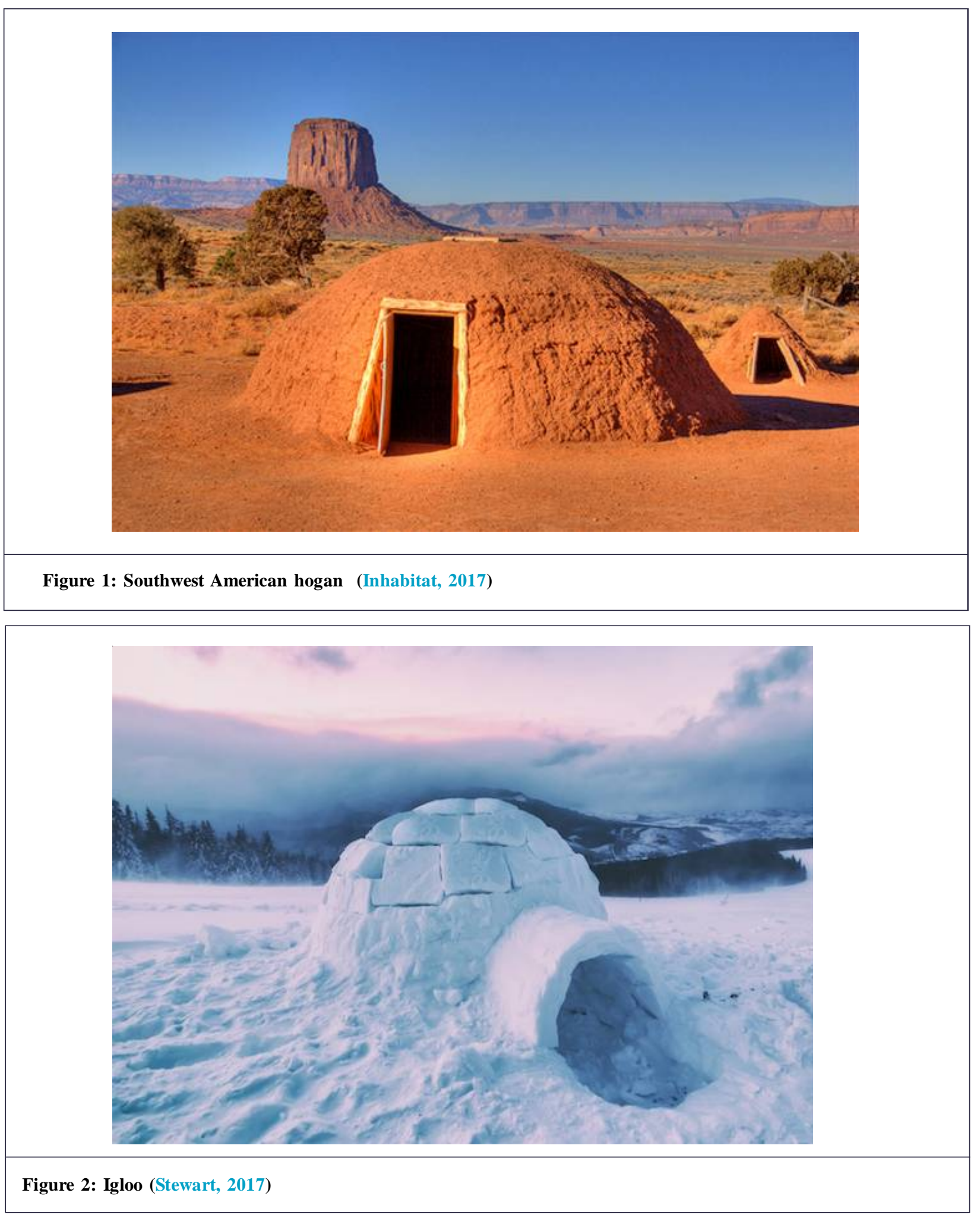

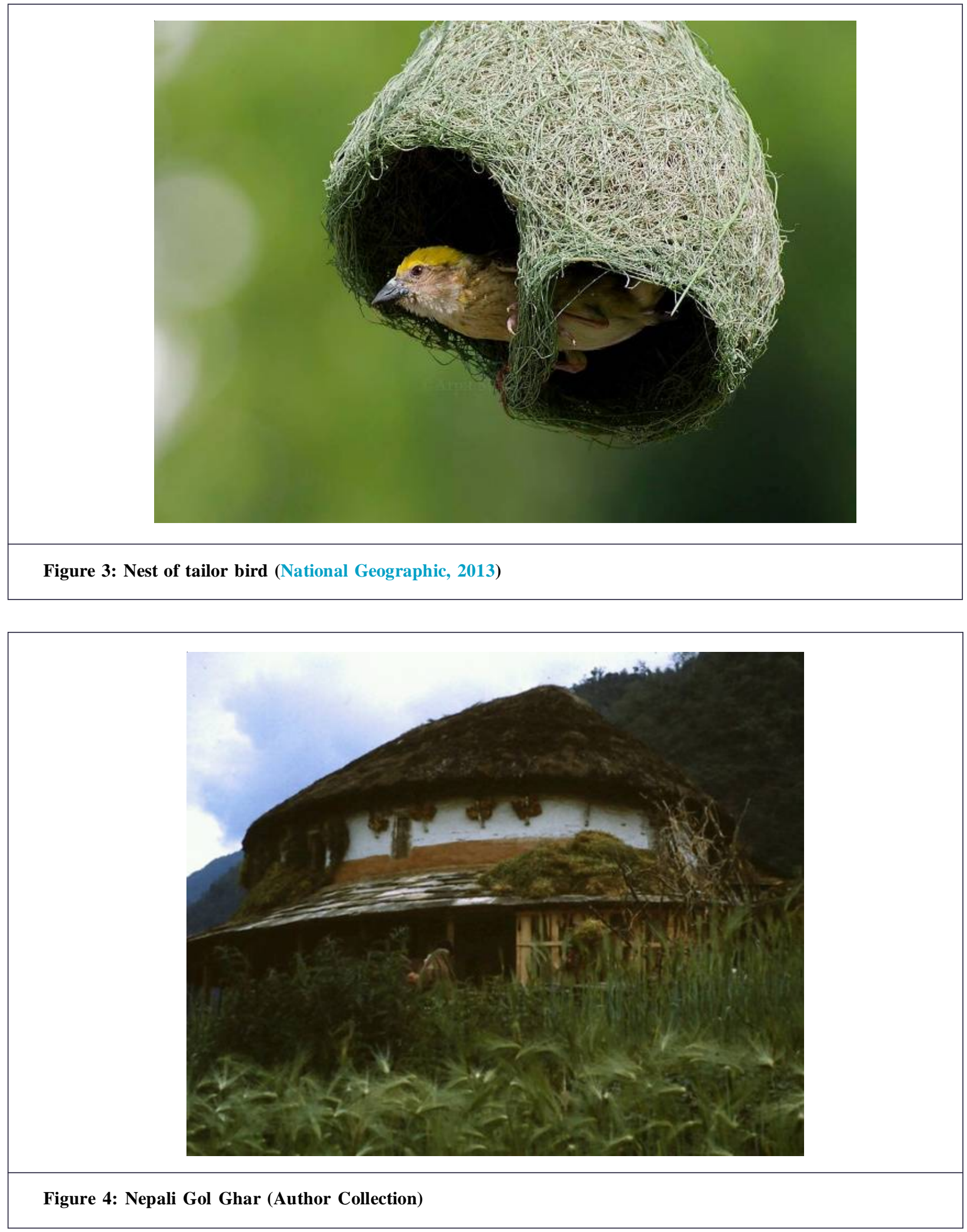

Why our ancestor had chosen and accepted to build circular shaped house? The main reason is the influence of what they see around the environment of Mother Nature (Ross, 2017). The shape of most of the natural elements is curved or circular shape, for, e.g., stones, tree trunks, eggs and the shape of earth itself (is said to be round). Humans started to build circular shaped houses inspired from the shelter made by other animals and birds (especially nests of the tailor bird or the swallow birds (Thapa, 2017)) which can be seen around their surrounding natural environment. While building shelter, not only physical protection but religious and cultural aspects also plays vital role (Rush, 2012). 
Circular shaped houses were developed in accordance to the nature as well as culture. Circular shaped houses are more comfortable, more energy efficient and safer (Ross, 2017) due to its architecture and science.

The main reason behind choosing and accepting the circular shaped houses by our ancestors can be discussed in various aspects. Major aspects are architectural, aesthetic, environmental, structural and psychological. Further discussion on these aspects is below:

\subsection{Architectural and structural aspect}

Circular shaped shelters are multi-sided polygons rather than true circles (Stewart, 2017). This allows the efficient use of today's commonly available building materials. The circular shape design allows for open floor plans, natural lighting and air circulation.

Round buildings use less wall, floor and roofing material to enclose the same square footage as a rectangular structure. It takes 15 to $20 \%$ less material as compared to create the same square-foot rectangular building (Ross, 2017). The self-supporting design of circular shaped houses allow desired placing of non-load bearing interior walls (Why Round, n.d.) which allows greater flexibility in designing interior spaces.

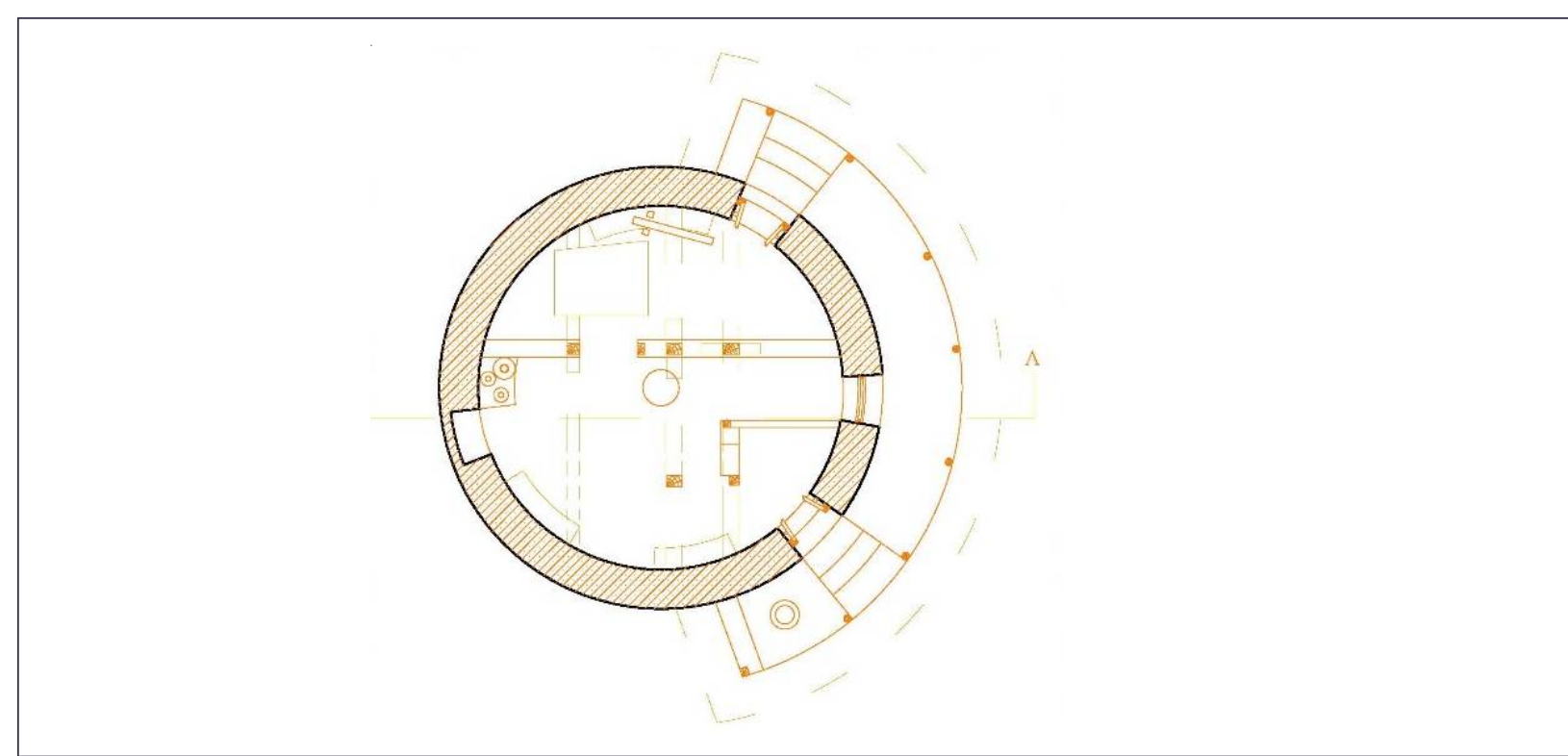

Figure 5: Floor plan of Gol Ghar (Author Collection)

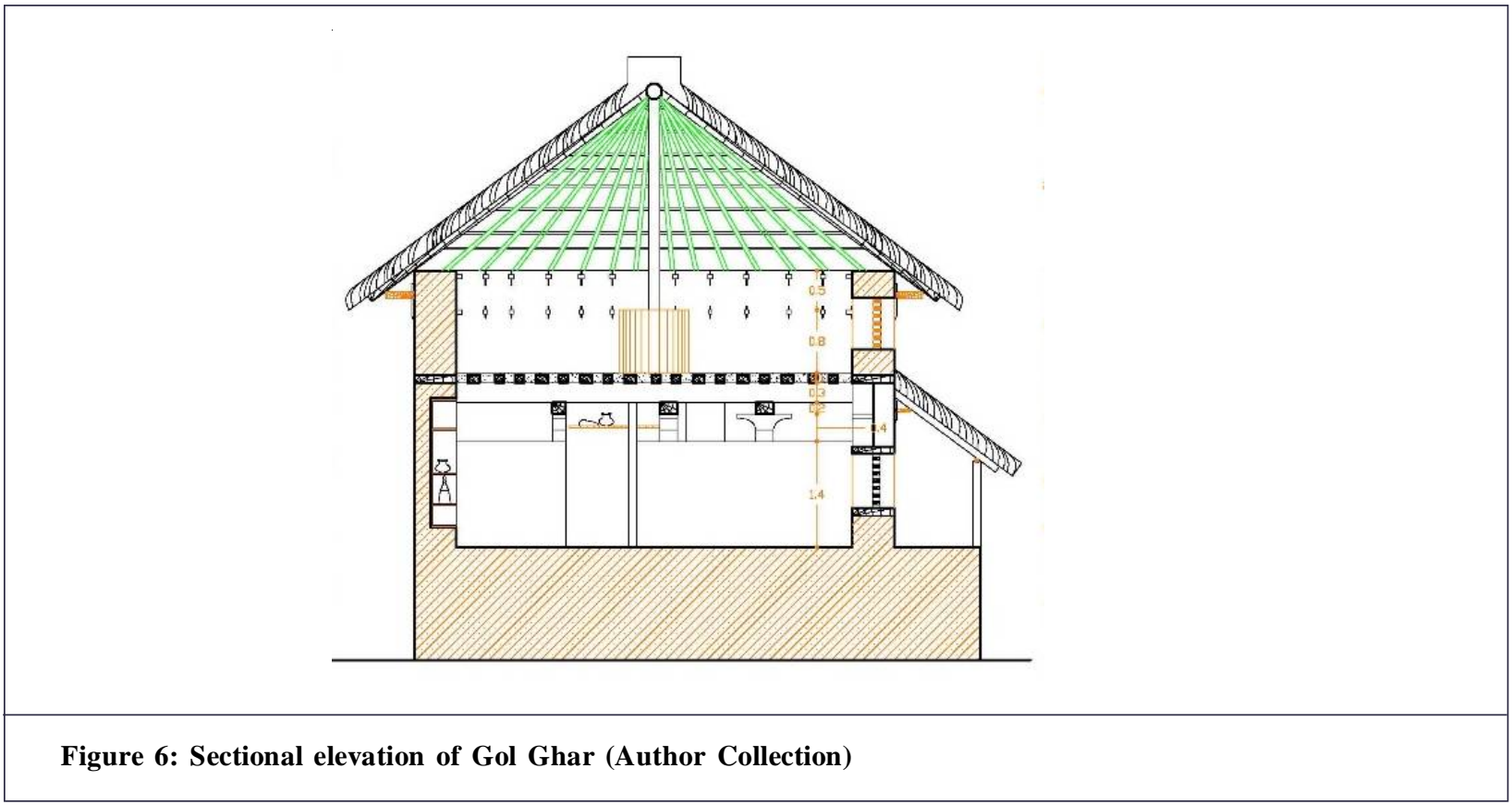


The roof structure of a round house incorporates a unique architectural design. Roof trusses meet in a centre ring, producing inward and outward pressure which holds the roof in a state of compression (Ross, 2017).

\subsection{Aesthetic aspect}

Aesthetically, curves and circles are a central and distinguishing feature of the natural world and circular buildings are incredibly fitting in a rural or forest environment. Round buildings are in prefect alignment with the current trends of the rural leisure and tourism industry, and satisfies the current demand for more integrated and natural structures which echo the sentiments of luxury glamping sites and holistic enterprises (Why Round, n.d.).

\subsection{Environmental aspect}

From an environmental perspective; round buildings reduce the amount of resources required due to the simple fact that a circle encloses the largest area for a given amount of perimeter, reducing the amount of material needed.

Round houses stand up to extreme weather. Their curved roofs make them wind resistant, less susceptible to highvelocity gusts lifting up the roof and tilting up the house (Stewart, 2017). As wind can flow around the circular structure, instead of getting hung up around the angles, these houses are particularly resistant to hurricanes and tornados. A circular structure withstands wind loads better than a square or rectangle. Since the wind hits a smaller portion of the wall surface and then flows around the structure, a round building typically withstands higher wind forces. The aerodynamic shape allows winds to move around a round building rather than developing destructive high and low air pressure areas that occur with flat walls (Why Round, n.d.). With the circular shape, each room can have two windows at an angle to one another (Dully, 1998). This allows for cool cross-ventilation in every room.

There are dozens of interconnected points in a round house. These are sites where builders can connect parts of the building together. In the old days, the connecting materials were rope, vine and hides. Modern materials are engineered components- like a centre radial steel ring, steel brackets, seismic and hurricane ties, bolts and steel cables. These connect the structural pieces and give the building a unique combination of flexibility and strength, qualities which causes them to be significantly safer in severe weather conditions like earthquakes, extreme winds and heavy snow-fall (Inhabitat, 2017).

\subsection{Psychological aspect}

Our ancestors also understood another, less measurable, aspect of circular living. Living in a round house provides a balance for looking inward and outward, looking out at the natural environment and surroundings but then coming in again to the self and the heart (Ross, 2017). As a social or workshop space the circular form is ideal for group work and gathering of people. Environmental psychologists have been writing papers for decades about the effects of our immediate environment on our well-being and we have come to recognize that a Roundhouse is a supportive cognitive environment which seems to connect people to each other and inadvertently, to the roots of our civilization (What are the advantages of round buildings?, n.d.).

\section{Conclusion}

Shelter is one of the basic ways to make the world, in terms that it makes hospitable to humans, that's why humans have developed themselves the skill of building shelter in a beautiful way, and has transferred to generations. Now, this architecture is called as an art. The oldest form of shelters made by humans were almost circular. Southwest American hogan, the Mongolian yurt, the North American tepee and Nepali Gol/Kudule Ghar are some of the representative example of indigenous circular shaped shelter around the world. The main reason behind building circular shaped shelter is the influence of Mother Nature. Since the shape of most of the natural element are curve or circular, for, e.g., stones, tree trunks, eggs, along with the shape of earth itself (is said to be round). Humans are also inspired to build circular shaped house from the shelter made by other animals (caves) and birds (nests) around their environment. Circular Shaped House are more comfortable, more energy efficient and safer due to its architecture and science. Today, architects are influenced by history in the breath-taking creation of circular shaped houses using modern materials and construction technologies. A 21 st-century round home built with modern materials can be a safe, efficient and healthy home of the future with roots in the past (Ross, 2017).

\section{Acknowledgment}

I would like to acknowledge and extend my heartfelt gratitude to the course tutor and my mentor Dr. Shree Hari Thapa for his constant guidance monitoring and encouragement throughout the course of this research and the preparation of an 
article. I would further like to thank my fellow classmates for helping and providing me the necessary guidance and information.

\section{References}

Dully, J. (1998). Circular house offers advantages over a regular, rectangular home. Retrieved March 08, 2019, from Dessert News: https://www.deseretnews.com/article/615535/Circular-house-offers-advantages-over-a-regularrectangular-home.html

Inhabitat. (2017). Retrieved March 08, 2019, from https://inhabitat.com/why-our-ancestors-built-round-houses-andwhy-it-still-makes-sense-to-build-round-structures-today/

National Geographic. (2013). Retrieved March 08, 2019, from https://blog.nationalgeographic.org/2013/07/27/top-25wild-bird-photographs-of-the-week-46-3/

Ross, R. (2017). Home work: The science of round buildings still holds up today. Retrieved March 08, 2019, from The Seattle Times: https://www.seattletimes.com/explore/nwhomes/homework-the-science-of-round-buildings-stillholds-up-today/

Rush, F. (2012). On Architecture: Thinking in Action. New York: Routledge Taylor and Francis Group.

Stewart, J. (2017). Eye-opening history of round homes and why curves matter in architecture. Retrieved March 08, 2019, from My Modern Met: https://mymodernmet.com/round-home-architecture/

Thapa, S. (2017). Analysis of Medieval Nepalese Architecture on the basis of Vernacular Architectural Texts. PhD Thesis in Nepalese History, Culture and Archaeology, Kathmandu.

What are the advantages of round buildings? (n.d.). Retrieved March 08, 2019, from Rotunda: https://rotunda.co.uk/ what-are-the-advantages-of-round-buildings/

Why Round. (n.d.). Retrieved March 08, 2019, from Full Circle Shelters, LLC: http:/fullcircleshelters.com/whyround.html

Cite this article as: Saurav Koirala (2021). Why our ancestor has accepted a circular shaped house?. International Journal of A rchitecture and Planning. 1(1), 24-29. doi: 10.51483/ IJA RP.1.1.2021.24-29. 